ing insulin and RBP4 levels at baseline in the group with a marginal response, as suggested by Oh, but rather dissociation between changes in fasting insulin and RBP4 levels after exercise. Baseline values in Table 2 of our article, analyzed with the use of the Wilcoxon rank-sum test, did not differ between the two groups.

Timothy E. Graham, M.D.

Beth Israel Deaconess Medical Center

Boston, MA 02215

Ulf Smith, M.D., Ph.D.

Sahlgrenska University Hospital

S-41345 Göteborg, Sweden

Barbara B. Kahn, M.D.

Beth Israel Deaconess Medical Center

Boston, MA 02215

bkahn@bidmc.harvard.edu
1. Matsumoto K, Miyake S, Yano M, et al. Glucose tolerance, insulin secretion, and insulin sensitivity in nonobese and obese Japanese subjects. Diabetes Care 1997;20:1562-8.

2. Kosaka K, Kuzuya T, Yoshinaga H, Hagura R. A prospective study of health check examinees for the development of noninsulin-dependent diabetes mellitus: relationship of the incidence of diabetes with the initial insulinogenic index and degree of obesity. Diabet Med 1996;13:Suppl 6:S120-S126.

3. Muggeo M, Zenti MG, Travia D, et al. Serum retinol levels throughout 2 years of cholesterol-lowering therapy. Metabolism 1995; 44:398-403.

4. Sasaki H, Iwasaki T, Kato S, Tada N. High retinol/retinolbinding protein ratio in noninsulin-dependent diabetes mellitus. Am J Med Sci 1995;310:177-82

5. Tripathy D, Almgren P, Tuomi T, Groop L. Contribution of insulin-stimulated glucose uptake and basal hepatic insulin sensitivity to surrogate measures of insulin sensitivity. Diabetes Care 2004;27:2204-10.

\title{
Molecular Mechanisms in Melanoma
}

TO THE EDITOR: The review of melanoma by Miller and Mihm (July 6 issue) ${ }^{1}$ clearly characterizes the linear progression of melanocytic lesions, from the morphologic perspective to the molecular perspective. ${ }^{2,3}$ However, the genetic alterations would have more relevance if they result in kinetic advantage and progression. My colleagues and I have studied a series of dysplastic nevi (92 low-grade and 31 high-grade lesions) and melanomas in situ (15 lesions) using proliferation (Ki-67 labeling), apoptosis (in situ end labeling), and cell-cycle regulators (RB1, TP53, p21WAF1, and p27Kip1). ${ }^{4}$ Our analysis highlighted a clear topographic heterogeneity at the early stage of melanocytic transformation: slow kinetics in the dermal compartment of low-grade melanocytic dysplasia and a higher incidence of TP53 alterations in high-grade melanocytic dysplasia than in low-grade dysplasia and melanomas. These findings suggest that melanocytic dysplasia is a marker of the risk of melanoma rather than a direct precursor.

SalvadorJ. Diaz-Cano, M.D., Ph.D.

King's College Hospital

London SE5 9RS, United Kingdom

salvador.diaz-cano@kcl.ac.uk

1. Miller AJ, Mihm MC Jr. Melanoma. N Engl J Med 2006;355: 51-65.

2. Meltzer PS. Genetic diversity in melanoma. N Engl J Med 2005;353:2104-7.

3. Bittner M, Meltzer P, Chen Y, et al. Molecular classification of cutaneous malignant melanoma by gene expression profiling. Nature 2000;406:536-40.
4. Pozo L, Naase M, Cerio R, Blanes A, Diaz-Cano SJ. Critical analysis of histologic criteria for grading atypical (dysplastic) melanocytic nevi. Am J Clin Pathol 2001;115:194-204.

TO THE EDITOR: Miller and Mihm suggest that the gene encoding the microphthalmia-associated transcription factor (MITF) is a key oncogene of the melanocytic lineage, since it was strongly amplified in 15 to $20 \%$ of metastatic melanomas. ${ }^{1,2}$ Furthermore, amplification of the MITF gene and overexpression of the MITF protein were associated with decreased overall survival among patients with metastatic melanoma. MITF overexpression was also associated with impaired sensitivity to cytotoxic agents in melanoma cell lines, suggesting that the number of copies of the MITF gene is a surrogate biomarker of the response to chemotherapy. ${ }^{2}$ To validate these findings, we investigated MITF gene amplification in tumor tissues from 90 patients with metastatic melanoma before the administration of individualized, sensitivity-directed chemotherapy. ${ }^{3}$ Strong amplification of the MITF gene (more than four copies per cell) was found in only 4 of 90 tumors (4.4\%), whereas 15 of 90 tumors (16.7\%) had intermediate amplification (more than two copies per cell). We found no association between the number of copies of the MITF gene and chemosensitivity, the outcome of chemotherapy, or overall survival. Hence, our findings suggest that the MITF gene 
has a smaller influence on melanoma than has been assumed previously.

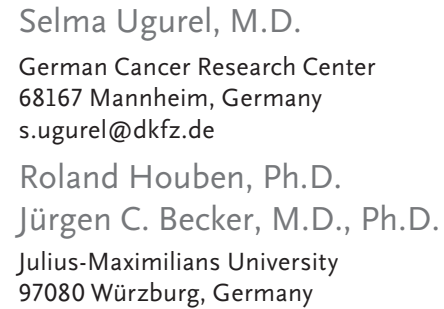

1. McGill GG, Horstmann M, Widlund HR, et al. Bcl2 regulation by the melanocyte master regulator Mitf modulates lineage survival and melanoma cell viability. Cell 2002;109:707-18.

2. Garraway LA, Widlund HR, Rubin MA, et al. Integrative genomic analyses identify MITF as a lineage survival oncogene amplified in malignant melanoma. Nature 2005;436:117-22.

3. Ugurel S, Schadendorf D, Pföhler C, et al. In vitro drug sensitivity predicts response and survival after individualized sensitivity-directed chemotherapy in metastatic melanoma - a multicenter phase II trial of the Dermatologic Cooperative Oncology Group (DeCOG). Clin Cancer Res (in press).

TO THE EDITOR: Miller and Mihm did not mention the role of epigenetic disturbances in melanoma. A number of genes are affected by alterations in DNA-methylation patterns in melanoma cells. ${ }^{1}$ Aggressive vertical growth can lead to metastasis, and it has been suggested that aberrant methylation of $\mathrm{CpG}$ islands may take place during this phase. ${ }^{1}$ This finding may have clinical application, since epigenetic inactivation or the action of tumor suppressors can be reversed by demethylating agents plus histone deacetylase inhibitors. $^{2}$

Salvador Vale, M.D.

Laboratorio Trinidad

01460 Distrito Federal, Mexico

svalemayorga@yahoo.com.mx
1. Gallagher WM, Bergin OE, Rafferty M, et al. Multiple markers for melanoma progression regulated by DNA methylation: insights from transcriptomic studies. Carcinogenesis 2005;26: 1856-67.

2. Glasspool RM, Teodoridis JM, Brown R. Epigenetics as a mechanism driving polygenic clinical drug resistance. Br J Cancer 2006;94:1087-92.

THE AUTHORS REPLY: The evidence in cell culture that MITF functions as an oncogene in conjunction with $B R A F^{1}$ provides a basis for the advantage that at least some melanomas gain by the overexpression of MITF. However, the previous observation that MITF is present in nearly all melanomas, ${ }^{2}$ despite its function in differentiation, indicates the need for melanomas to maintain the expression of MITF.

This phenomenon of dependence of a tumor on lineage-specific genes ${ }^{3}$ suggests that further knowledge of the role of MITF in the survival and development of normal melanoctyes is essential for understanding the "addiction" of melanoma to the MITF-driven genetic program.

Arlo Miller, M.D., Ph.D.

Martin C. Mihm, Jr., M.D.

Massachusetts General Hospital

Boston, MA 02114

1. Garraway LA, Widlund HR, Rubin MA, et al. Integrative genomic analyses identify MITF as a lineage survival oncogene amplified in malignant melanoma. Nature 2005;436:117-22.

2. Granter SR, Weilbaecher KN, Quigley C, Fisher DE. Role for microphthalmia transcription factor in the diagnosis of metastatic malignant melanoma. Appl Immunohistochem Mol Morphol 2002;10:47-51.

3. Garraway LA, Sellers WR. Lineage dependency and lineagesurvival oncogenes in human cancer. Nat Rev Cancer 2006;6:593602.

\section{Alemtuzumab for Refractory Celiac Disease}

TO THE EDITOR: Vivas et al. (June 8 issue) ${ }^{1}$ describe a patient with refractory celiac disease who had a response to treatment with alemtuzumab. It is not clear whether the percentage of aberrant intraepithelial lymphocytes decreased while the patient was receiving alemtuzumab, since only $\gamma \delta$ T cells are mentioned. However, the aberrant T-cell population $(\mathrm{CD} 7+\mathrm{CD} 3-\mathrm{CD} 4-\mathrm{CD} 8$ - cytoplasmic $\mathrm{CD} 3+)$ determines the risk of enteropathyassociated T-cell lymphoma. This population is distinct from the population of $\gamma \delta$ T cells. ${ }^{2,3}$
We report on a 66-year-old woman who had refractory celiac disease with progressively more aberrant intraepithelial lymphocytes despite treatment with alemtuzumab. The patient had been on a gluten-free diet and had undergone therapy with prednisone and cladribine. Duodenal biopsy showed persistent total villous atrophy. Flow cytometry of intraepithelial lymphocytes revealed that $60 \%$ were aberrant. The percentage of $\gamma \delta \mathrm{T}$ cells was only $1 \%$.

Alemtuzumab was started. Although we ob- 